\section{Myopericarditis After COVID-19 mRNA Vaccination}

Shintaro Sakaguchi, MD; Naoki Fujimoto, MD, PhD; Kazuhide Ichikawa, MD, PhD; Daisuke Izumi, MD; Koji Katsuta, MD, PhD; Masafumi Takafuji, MD; Kyoko Imanaka-Yoshida, MD, PhD; Kaoru Dohi, MD, PhD

A previously healthy 49-year-old man presented to hospital 11 days after a 2nd dose of the BNT162b2mRNA (Pfizer-BioNTech) vaccine for essential workers. He began to notice fever, appetite loss, cough, and orthopnea 4 days after vaccination. Oral nonsteroidal anti-inflammatory drug and antibiotics for several days failed to relieve his symptoms. On admission, physical examination revealed fever of $37.3^{\circ} \mathrm{C}$, blood pressure of $95 / 67 \mathrm{mmHg}$, pulse of 93 beats/min and pericardial friction rub on auscultation. ECG demonstrated low voltage in the limb leads and poor R waves in V1-2. Chest X-ray showed mild congestion (Figure A). Laboratory evaluation showed elevated B-type natriuretic peptide of $1,113.0 \mathrm{pg} / \mathrm{mL}$, troponin I of $4,364.5 \mathrm{pg} / \mathrm{mL}$, and C-reactive protein of $19.78 \mathrm{mg} / \mathrm{mL}$. Blood cell count was normal with no peripheral eosinophilia. Nasopharyngeal SARS CoV-2 antigen and other viral studies were negative. Cardiac magnetic resonance imaging (CMR) showed diffuse myocardial edema on T2-weighted imaging (Figure B), reduced left ventricular ejection fraction of $33 \%$, diffuse late gadolinium enhancement (LGE), and increased global native $\mathrm{T} 1$ value of $1,301 \mathrm{~ms}$ (Figure $\mathbf{C}$ ). Endomyocardial biopsy revealed diffuse lymphocytic infiltrates and some eosinophils (Figure D), confirming the diagnosis of myocar- ditis. Oral diuretics and aspirin relieved his symptoms. CMR on day 12 showed resolution of the myocardial edema (Figure E), decrease in the native T1 value to $1,176 \mathrm{~ms}$ (Figure F), and partial LGE. He was discharged home on day 15 .

To our knowledge, this is the first case of presumed COVID-19 vaccine-related myocarditis diagnosed by myocardial biopsy and CMR in a middle-aged man. Although myocarditis following COVID-19 vaccine can be mild and occur in the young, ${ }^{1}$ more intense myocarditis might occur in individuals of any age. Thus, careful attention to myocarditis is necessary.

\section{Disclosure}

K.I.-Y. received an independent medical educational grant $>1,000,000$ yen from Pfizer Japan Inc.

\section{Reference}

1. Montgomery J, Ryan M, Engler R, Hoffman D, McClenathan $\mathrm{B}$, Collins L, et al. Myocarditis following immunization with mRNA COVID-19 vaccines in members of the US military. JAMA Cardiol 2021; e212833. doi:10.1001/jamacardio.2021.2833.

Received August 2, 2021; revised manuscript received August 10, 2021; accepted August 12, 2021; J-STAGE Advance Publication released online September 30, 2021 Time for primary review: 6 days

Department of Cardiology (S.S., K.I., D.I.), Department of Pathology (K.K.), Matsusaka Municipal Hospital, Matsusaka; Department of Cardiology and Nephrology (N.F., K.D.), Department of Radiology (M.T.), Department of Pathology and Matrix Biology (K.I.-Y.), Mie Universal Graduate School of Medicine, Tsu, Japan

Mailing address: Naoki Fujimoto, MD, PhD, Department of Cardiology and Nephrology, Mie Universal Graduate School of Medicine, 2-174 Edobashi, Tsu 514-8507, Japan. E-mail: naokifujimo@clin. medic.mie-u.ac.jp

All rights are reserved to the Japanese Circulation Society. For permissions, please e-mail: cj@j-circ.or.jp ISSN-1346-9843

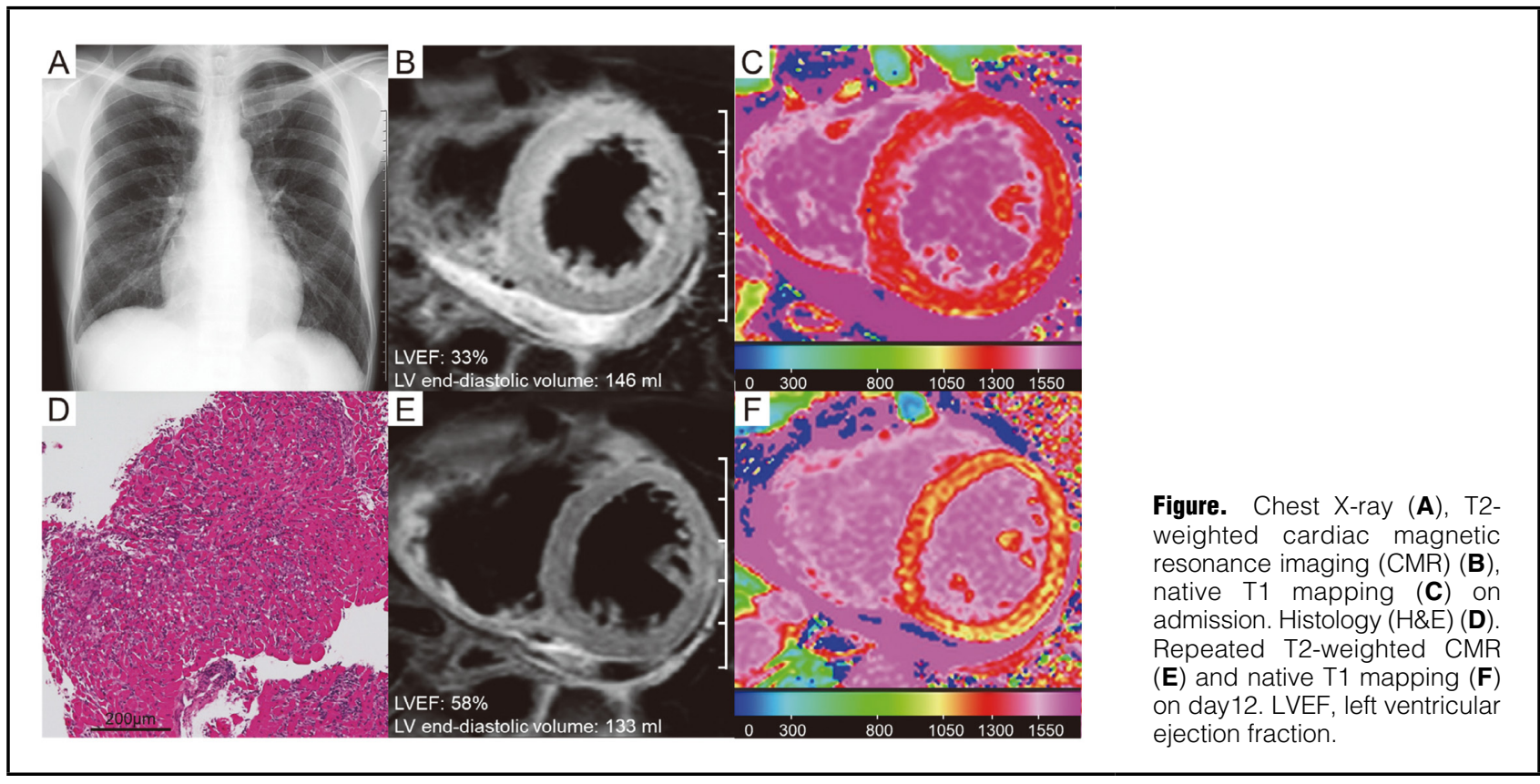

